\title{
Strength Characterization of Fiber Reinforced Cement-Fly Ash Mixes
}

\author{
Hemant Sharad Chore $^{1}$ (D) Mahendra K. Vaidya ${ }^{1}$
}

Received: 30 April 2015/Accepted: 3 September 2015/Published online: 16 September 2015

(C) Springer International Publishing AG 2015

\begin{abstract}
The experimental investigation for the characterization of strength of fiber reinforced cement-fly ash mixes is presented in this paper. The objective of the investigation was to quantify the optimum quantity of cement contents and randomly distributed polypropylene fibers on the performance of cement stabilized and fiber reinforced fly ash mixes. Four samples of the mixes were considered in this investigation. For each sample, the fly ash was replaced by 5, 10, 15 and $20 \%$ cement content, respectively. Similarly, the contents of the fibers were also varied by $0,0.5,1$, and $1.5 \%$, respectively. The aspect of soaking was also considered. The samples were cured for 7, 14 and 28 days respectively. For the purpose of evaluation, unconfined compressive strength test and Brazilian (i.e., indirect) tensile strength test were conducted. The results obtained indicate significant improvement in strength with the inclusion of fibers and cement. The investigation underscores the effective utilization of pozzolanic waste such as fly ash as a civil engineering material.
\end{abstract}

Keywords Fly ash · Polypropylene fibers · Curing period - Soaking $\cdot$ Unconfined compressive strength (UCS) - Brazilian tensile strength (BTS)

Hemant Sharad Chore

hschore@ rediffmail.com

1 Department of Civil Engineering, Datta Meghe College of Engineering, Sector-3, Airoli, New Mumbai 400708, India

\section{Introduction}

The environmentally acceptable disposal of the fly ash, being produced in millions of tonnes, has become an increasing concern for the researchers. Several research works have established that the fly ash has pozzolanic properties and hence, could be used as a cement replacing material in this era of emergence of sustainable construction materials. Fly ash is being utilized on a large scale in geotechnical construction such as embankments, road sub bases, structural land fill, etc. either independently or in conjunction with various types of fibers. There are several investigations available in the literature reporting improvement in the properties and strength parameters of the weak materials using pozzolanic materials and fibers.

Several researchers $[1-3]$ investigated the performance of different types of sands in conjunction with fibers alone or in conjunction of fly ash and fibers. Kaniraj and Havanagi [1] studied the soil-fly ash mixture with $1 \%$ polyster fibers of $20 \mathrm{~mm}$ length and found significant effect of fly ash and fiber on the performance of soil. Chauhan et al. [2] carried out extensive laboratory investigations to study the performance evaluation of silty-sand subgrade reinforced with fly ash and fiber reinforcement (coir fibers and synthetic fibers). The study indicated that the coir fibers show better resilient response against the synthetic fibers due to higher coefficient of friction. Chore et al. [3] reported performance studies of sand-fly ash mixture reinforced with polypropylene fibers and the effect of fiber content and fly ash was examined on the CBR and angle of internal friction. The study revealed that the optimum percent of fiber and fly ash was 1 and $50 \%$, respectively.

Sadek et al. [4] reported an experimental investigation for evaluating the shear strength of fiber reinforced sand. The addition of fibers with an aspect ratio ranging from 40 
to 150 and fiber content ranging from 0.5 to $1.5 \%$ was found to increase the shear strength and the ductility of sand-fiber composite. Further, longer fibers were found to improve the strength considerably. Kumar et al. [5] studied the effect of randomly distributed polypropylene fibers on fly ash embankments through laboratory and field tests. The investigation indicated significant improvement in CBR value, angle of internal friction and modulus of subgrade reaction. Teng et al. [6] reported the stabilization of clayey soil with cement and fibers. It was observed that the fiber reinforcement increased UCS and shear strength. Kalantari et al. [7] reported the strengthening of peat with cement and polypropylene fibers by conducting UCS and CBR tests. It was suggested that the cement stabilized and fiber reinforced peat can be used as the base course material in the pavement construction.

Few studies $[8,9]$ reported the utilization of only fly ash along with the fibers. Kaniraj and Gayatri [8] reported the experimental studies on the geotechnical behavior of fly ash mixed with randomly oriented polyster fiber inclusions. The study revealed that the inclusion of fiber increased the strength of raw fly ash specimens and changed their brittle behavior into ductile behavior. Kumar and Singh [9] studied extensively the effects of polypropylene fiber reinforcements on the conventional parameters of fly ash such as UCS, modulus of elasticity, shear strength and CBR; and also on the permanent strength, resilient strain and resilient modulus of fly ash. Based on the results, it was concluded that fly ash is suitable in sub-base if it is reinforced with polypropylene fibers.

The review of literature indicates that a relatively less amount of work is reported in respect of the combined influence of fiber reinforcement and cement stabilization on the behaviour of fly ashes. Based on this, an experimental study was undertaken to conduct the performance studies of fly ash stabilized with different percentages of cement and polypropylene fibers for different curing periods in respect of soaked and un-soaked conditions. From the literature review, it is seen that addition of around $15 \%$ of lime would suffice when used in the soil-fly ash mixes. The fiber reinforced fly ash-lime mix may not yield the required strength when it is proposed to be used in the pavement as sub-base. In view of this, an effort was made to try the suitability of fiber reinforced and cement stabilized fly ash mixes with $20 \%$ cement content as an upper bound. The limited study in this regard was reported in the recent past by the authors [10]. This study was extended further to account for higher curing period. The comprehensive investigation extended based on the previous study [10] is reported in this paper. The investigation was aimed at quantifying the optimum quantity of fibers and cement on compressive and tensile strength.

\section{Materials, Experimental Programme and Methodology}

\section{Materials}

In this experimental study, the materials, fly ash, polypropylene fibers and ordinary Portland cement (OPC), were used.

Fly Ash

The fly ash was supplied by M/s Dirk India Private Limited, Eklahare Nasik, Maharashtra, India (Source: Nasik Thermal Power Station). The chemical and physical properties of the fly ash were provided by the supplier and are shown in Table 1.

\section{Polypropylene Fibers}

The polypropylene fibers used in the present investigation were supplied by M/s RMC Readymix (India) Pvt. Ltd., Ghatkopar, Mumbai, India. The fibers used in this investigation were modified virgin polypropylene. They were hydrophobic, non-corrosive and resistant to alkalis, chemicals and chlorides. The characteristics of the fibers were provided by the suppliers and are given in Table 2 .

\section{Ordinary Portland Cement (OPC)}

The cement comprised OPC (ACC Cement of 53 Grade, i.e., the cement with characteristic compressive strength of

Table 1 Chemical and physical properties of fly ash

\begin{tabular}{ll}
\hline Property & Value $(\%)$ \\
\hline Chemical composition & \\
Silica $\left(\mathrm{SiO}_{2}\right)$ & 58.040 \\
Alumina $\left(\mathrm{Al}_{2} \mathrm{O}_{3}\right)$ & 25.71 \\
Ferric oxide $\left(\mathrm{Fe}_{2} \mathrm{O}_{3}\right)$ & 5.31 \\
Sulphur tri oxide $\left(\mathrm{SO}_{3}\right)$ & 0.677 \\
Calcium oxide $(\mathrm{CaO})$ & 5.59 \\
Titanium oxide $\left(\mathrm{TiO}_{2}\right)$ & 1.30 \\
Magnesium oxide $(\mathrm{MgO})$ & 1.589 \\
Sodium oxide $\left(\mathrm{Na}{ }_{2} \mathrm{O}\right)$ & 0.601 \\
Potassium oxide $\left(\mathrm{K}_{2} \mathrm{O}\right)$ & 0.60 \\
Physical properties & \\
Specific gravity & 2.13 \\
Liquid limit & - \\
Shrinkage limit & 30.42 \\
Loss of ignition & 1.071 \\
Moisture (\%) & 0.267 \\
Soil classification of fly ash & ML \\
\hline
\end{tabular}


Table 2 Characteristics of polypropylene fibers

\begin{tabular}{ll}
\hline Property & Value \\
\hline Length (mm) & 60 \\
Specific gravity & 0.91 \\
Elongation & $15 \%$ \\
Nature & Inert \\
Water absorbing capacity & Nil \\
Tensile strength & $450 \mathrm{MPa}$ \\
Melting point $\left({ }^{\circ} \mathrm{C}\right)$ & 165 \\
Heat resistance $\left({ }^{\circ} \mathrm{C}\right)$ & $<130$ \\
\hline
\end{tabular}

$53 \mathrm{MPa}$ after 28 days' curing) which was made available by M/s RMC Readymix (India) Pvt. Ltd., Ghatkopar, Mumbai, India. The characteristics of the cement were tested in the laboratory of the supplier in accordance with the specifications brought out by Bureau of Indian Standards (BIS) [11] and are given in Table 3.

\section{Experimental Programme and Methodology}

The experimental programme involved in the present investigation comprised the following tests: Atterberg's limits (liquid limit and plastic limit), standard Proctor tests for finding out optimum moisture content (OMC) and maximum dry unit weight $\left(\gamma_{\mathrm{d} \max }\right)$, UCS and Brazilian tensile strength (BTS) tests. These tests were carried out on various combinations of fiber reinforced fly ash-cement mixes.

The performance of a total of 16 stabilized fly ash mixes was investigated by varying the percentage of cement and polypropylene fibers. For each mix, two samples were prepared. The fly ash was replaced by cement contents of 5 , 10,15 and $20 \%$, respectively, on dry weight basis. Further,

Table 3 Characteristics of cement

\begin{tabular}{ll}
\hline Normal consistency & \\
\hline Required water for normal consistency & $110 \mathrm{ml}$ \\
$\%$ of normal consistency & $27.5 \%$ \\
Setting time & $150 \mathrm{~min}$ \\
Initial setting time & $225 \mathrm{~min}$ \\
Final setting time & 3.03 \\
Specific gravity & 310.83 \\
Specific surface & \\
Compressive strength (MPa) & 27 \\
3 days & 37 \\
7 days & 53 \\
\hline days & \\
\hline
\end{tabular}

four values of fibers, i.e., $0,0.5,1$, and $1.5 \%$ were considered for each of these mixes. The specimens were cured in air for 7, 14 and 28 days using an air curing technique that entailed letting the samples remain at normal air temperature $\left(28^{\circ} \mathrm{C}\right)$. Depending upon the mix proportions, the required amount of ingredient were mixed thoroughly in a dry state and the specimens were prepared in desiccators for humidity control curing.

In actual practice, the stabilized fly ash may be subjected to inundation in the field to assess the effect of soaking. In view of this, two series of tests were conducted on unsoaked and soaked specimens compacted at the OMC. For soaking, the specimens were immersed in water for 8-10 hours after curing.

\section{Results and Discussion}

\section{Compaction Tests}

Before preparation of the sample, the OMC and maximum dry unit weight $\left(\gamma_{\mathrm{d}} \max \right)$ were calculated for sixteen mixes using standard Proctor test [12]. Their values observed in respect of the various combinations of cement-fly ashfibers mixes are given in Table 4. It may be noted that while the fly ash was found to be non-plastic, its liquid limit value was found to be 21 .

In the case of an un-reinforced mix, the maximum dry unit weight is found to increase with cement contents. In case of all the cement based mixes, it increases up to $1 \%$ fiber contents and thereafter, decreases. From this, it is seen that the value of maximum dry unit weight is generally less in the case of unreinforced mix as compared to the reinforced mix. However, the variation is not significant.

Setty and Rao [13] reported an increase in maximum dry unit weight and OMC ( $\left.W_{\text {opt }}\right)$ with increase in fiber contents with respect to silty sand mixed with polypropylene fibers. Only two fiber contents $(0.5$ and $1 \%)$ were used. The trend of in maximum dry unit weight and OMC observed in the present investigation is similar to that reported in the literature [13]. The polypropylene fibers absorb water which tends to increase OMC. However, this is true up to the $1 \%$ fiber contents. With the higher fiber contents such as $1.5 \%$, the maximum dry unit weight and OMC are found to decrease. The trend is different at higher fiber contents than that reported in the literature [13]. This could be attributed to the difference in the materials. Setty and Rao [13] dealt with silty sand-polypropylene fiber mix whereas the present investigation deals with the fly ash-cementpolypropylene fiber mix and at higher fiber contents, the effect of pozzolanic materials could have such effect on the in maximum dry unit weight and OMC. 
Table 4 Values of maximum dry unit weight $\left(\gamma_{d \max }\right)$ and optimum moisture contents (OMC)

\begin{tabular}{llllllll}
\hline Cement $(\%)$ & Fibers $(\%)$ & $\gamma_{\mathrm{d} \max }\left(\mathrm{kN} / \mathrm{m}^{3}\right)$ & $W_{\text {opt }}(\%)$ & Cement $(\%)$ & Fibers $(\%)$ & $\gamma_{\mathrm{d} \text { max }}\left(\mathrm{kN} / \mathrm{m}^{3}\right)$ & $W_{\text {opt }}(\%)$ \\
\hline 5 & 0 & 13.5 & 18.80 & 15 & 0 & 14.0 & 19.30 \\
5 & 0.5 & 13.7 & 20.40 & 15 & 0.5 & 1.0 & 14.0 \\
5 & 1.0 & 13.8 & 20.50 & 15 & 1.5 & 13.8 & 14.1 \\
5 & 1.5 & 13.6 & 20.20 & 15 & 0 & 20.85 \\
10 & 0 & 13.8 & 20.80 & 20 & 0.5 & 14.2 & 20.45 \\
10 & 0.5 & 13.8 & 21.00 & 20 & 1.0 & 14.3 & 20.30 \\
10 & 1.0 & 14.0 & 21.40 & 20 & 1.5 & 20.85 \\
10 & 1.5 & 13.7 & 21.20 & 20 & & 14.0 \\
\hline
\end{tabular}

\section{Unconfined Compressive Strength (UCS)}

The UCS tests were carried out on various mixes considered in the present investigation. The unconfined compression test [14] is a special case of triaxial compression test in which the axial compressive stress only is applied to the cylindrical specimen. The effect of various aspects such as cement and fiber contents in the stabilized mixes along with that of curing period and the soaking condition, on the UCS is discussed in this section. The values of UCS in respect of the various mixes are indicated in Fig. 1. It is observed that the UCS of the stabilized mixes of fly ash and cement is found to increase with the addition of cement content as this acts as a binding agent. The increase in UCS with the addition of cement is attributed to increase in the availability of alkali (which is a by-product of hydration of cement) for pozzolanic reaction. Further, the rate of gain in the strength is found to increase as the cement content increases. The maximum strength is observed for the stabilized mix having $20 \%$ cement content.

The UCS of cement stabilized fly ash mixes was found to reduce due to soaking irrespective of the mix proportion and curing period. For un-soaked specimens, there is a possibility of suction development in the pore fluid which gives rise to high compressive strength. Soaking the specimens may fill the voids to a certain extent and reduce the chances of development of suction in the pore fluid. While soaking, the softening of specimens may take place reducing the strength. In this investigation, it was observed that the strength had reduced when the specimens were soaked for 10 hours which implies that the two mechanisms - probability of low suction development in soaked specimens and softening of the specimens might have dominated over the gain of strength due to pozzolanic reaction in the presence of sufficient moisture.

The variation of UCS with the addition of randomly distributed polypropylene fibers in the cement stabilized fly ash mixes having different cement contents for various curing periods considered in the present investigation is shown in Fig. 1. It is seen that the UCS increases with fiber contents up to $1 \%$ and thereafter, decreases with further addition of fiber contents (i.e. $1.5 \%$ ). However, there is certain exception. In respect of the mix cured for 14 days and having $15 \%$ cement content, the compressive strength is found to decrease with the addition of fibers up to $1 \%$ and thereafter, increase with further addition of fibers. It can be said that all the mixes having different cement contents and various curing period yields optimum performance at $1 \%$ fiber content.

The UCS of all mixes was found to increase with an increase in the curing period. The pozzolanic reaction accelerates during the first stage of curing, i.e., 7 days' curing. Therefore, rapid gain in strength of the mixes is observed in this stage; but thereafter, the rate of gain in strength is found to decrease with further increase in the curing period. In case of the mix with $5 \%$ cement content and for $0.5 \%$ fiber content, the percentage increase during the first and second stage of curing is found to be $148-156 \%$ and $16.27-32 \%$ on an average, respectively. With further increase in the fiber content ( 1 and $1.5 \%$ ) for the same mix, the increase in the strength is found to be $26.72-55 \%$ and $12.33-38.5 \%$ on an average, respectively. It can be seen that for the mix with $5 \%$ cement contents, the increase in either stage is gradual. For the mix with $10 \%$ cement contents, the increase in the strength during the first stage of curing is observed to be $106 \%$ on an average and this increase is found to reduce to $36 \%$ for the fiber contents ranging from 0.5 to $1.5 \%$. However, in case of unreinforced mix having $10 \%$ cement contents, the increase is gradual, i.e., 60 and $39.27 \%$, respectively. For the unreinforced mix having $15 \%$ cement content and for all cases of reinforced mixes, the increase in the strength in either stage of curing seems to be marginal, i.e., 85 and $47 \%$ on an average, respectively. For higher cement content considered in the present study, i.e., $20 \%$, the increase is observed to be rapid during the first stage of curing $(110 \%)$ and reduces thereafter to $39 \%$ when no fibers are added. However, with addition of fibers from 0.5 to $1.5 \%$, the increase in either phase of curing is observed to be 84 and $33 \%$, respectively. 
Fig. 1 Variation in UCS with percentage of fibers content for different curing period (a) 7 days' curing, (b) 14 days' curing and (c) 28 days' curing

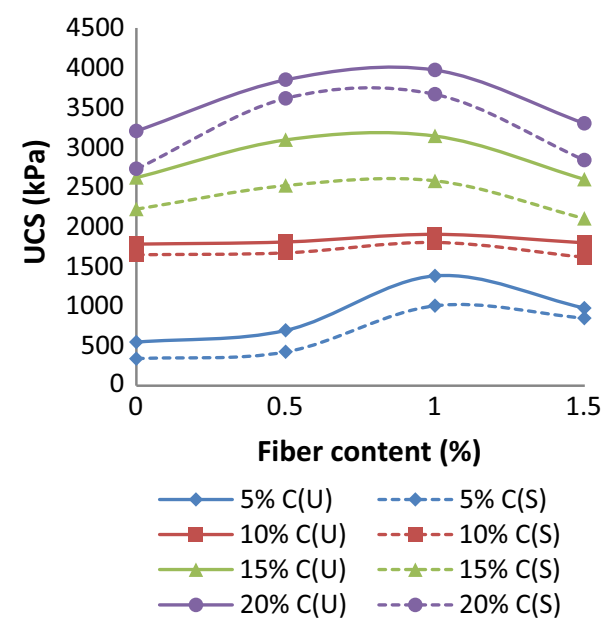

(a)

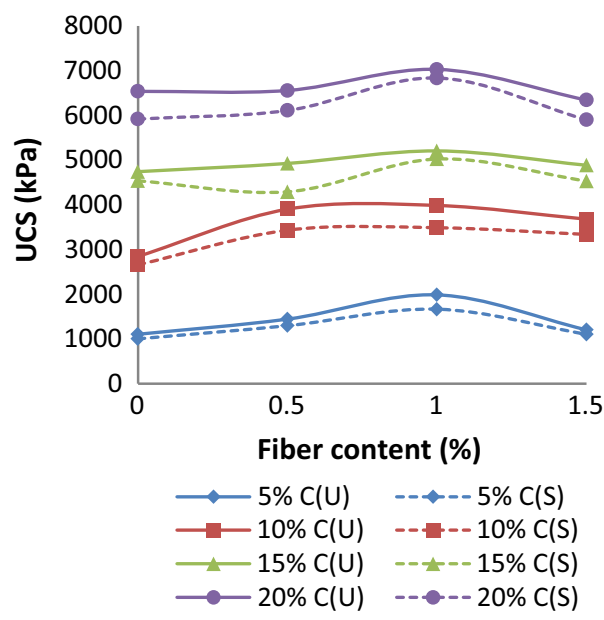

(b)

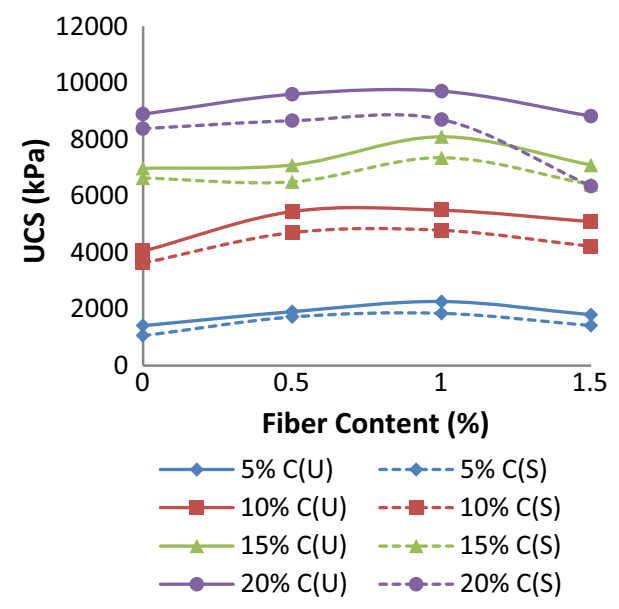

(c)

Table 5 Unconfined compressive strength $(\mathrm{kPa})$ of cement stabilized and fiber reinforced fly ash specimens

\begin{tabular}{lllll}
\hline & Cement & \multicolumn{3}{l}{ Curing period (days) } \\
\cline { 3 - 5 } & Contents & 7 & 14 & 28 \\
\hline Kaniraj and Havanagi [1] & 3 & 138.3 & 186.3 & 271.7 \\
& 6 & 483.5 & 691.4 & 918.9 \\
Present study & 5 & 1006 & 1668 & 1846 \\
\hline
\end{tabular}

The values of the UCS in respect of the cement stabilized fiber reinforced fly ash mixes, air cured for 7, 14 and 28 days, reported by Kaniraj and Havanagi [1] are given in Table 5. The cement contents were varied as 3 and $6 \%$ whereas $1 \%$ polyster fibers were considered. The values of the UCS with $5 \%$ cement contents and $1 \%$ polypropylene fibers obtained in the present investigation are also given in Table 5 for the purpose of comparison.
The values of UCS obtained in the present investigation with $5 \%$ cement contents are found to be on higher side as compared to that reported in the literature [1] where $6 \%$ cement contents were used. Although the values of UCS as seen in the present investigation are on higher side as compared to that reported in the literature [1] with even $1 \%$ less cement contents, such variation could be attributed to the difference in the fibers used. The present investigation used polypropylene fibers whereas Kaniraj and Havanagi [1] used polyster fibers. All the same, trend in increase in UCS with curing and cement contents observed in the study [1] holds good in the present investigation.

\section{Brazilian Tensile Strength (BTS)}

Although the tensile strength is of more relevance in respect of rocks, the fly ash when used in the sub-base of the pavement should have some tensile strength. In view of this, the tensile strength of the mixes considered in the 
present investigation was evaluated. The BTS as obtained from indirect tensile test in respect of the various mixes are indicated in Fig. 2.

The BTS was found to increase with an increase in cement content. Further, the values of BTS of un-soaked mixes were found to be higher. The effect of soaking on the tensile strength of various mixes considered in the present investigation was similar to that observed in case of the evaluation of effect of soaking on UCS. The soaking of specimen was found to reduce the tensile strength of the stabilized mixes irrespective of mix proportion and curing period. The reasons cited for this trend in the preceding section holds good here as well.

The effect of fiber contents on the tensile strength of cement stabilized fly ash mixes having different cement contents for 7, 14, and 28 days curing period is indicated in Fig. 2. It is observed that the tensile strength increases with increase in fiber contents up to $1 \%$ fiber in respect of almost all the mixes (un soaked and soaked) cured for 7, 14 and 28 days, barring few exceptions. In respect of the soaked mixes containing 15 and $20 \%$ cement contents and cured for 14 days', the strength is found to reduce initially with $0.5 \%$ fiber contents and thereafter, increases with increase in fiber contents up to $1 \%$ fiber. However, in all the mixes, the strength is found to decrease with further addition of fibers amounting to $1.5 \%$ fiber contents. The maximum value of tensile strength is observed for $20 \%$ cement content. In a nutshell, the addition of cement is found to increase the tensile strength of the cement stabilized fly ash mixes due to increase in the availability of alkali (which is a by-product of hydration of cement) for pozzolanic reaction.

When the increase in strength during two different phases of curing (7-14 and 14-28 days) is considered with reference to addition of cement contents, for the mix containing $5 \%$ cement, the average gain in strength is found to be $36 \%$
Fig. 2 Variation in BTS with percentage of fibers content for different curing period (a) 7 days' curing, (b) 14 days' curing and (c) 28 days' curing

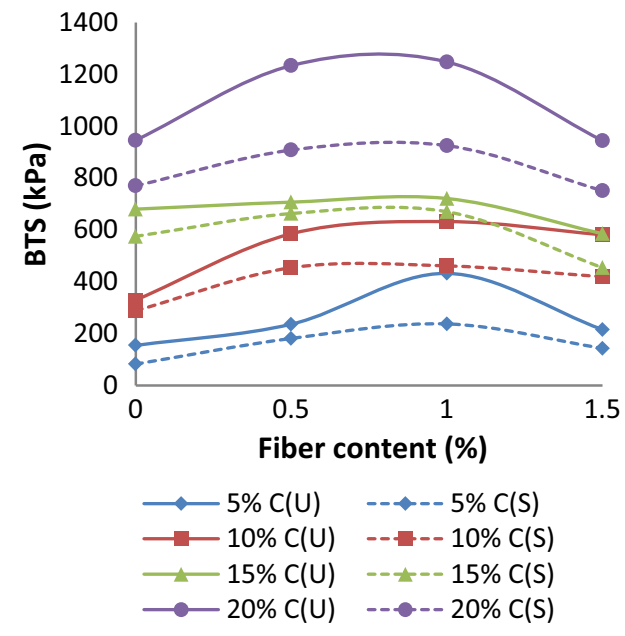

(a)

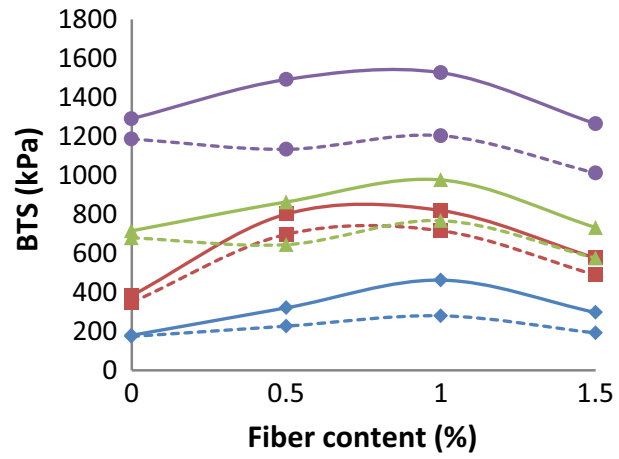

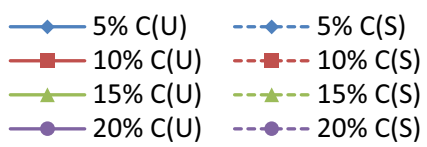

(b)
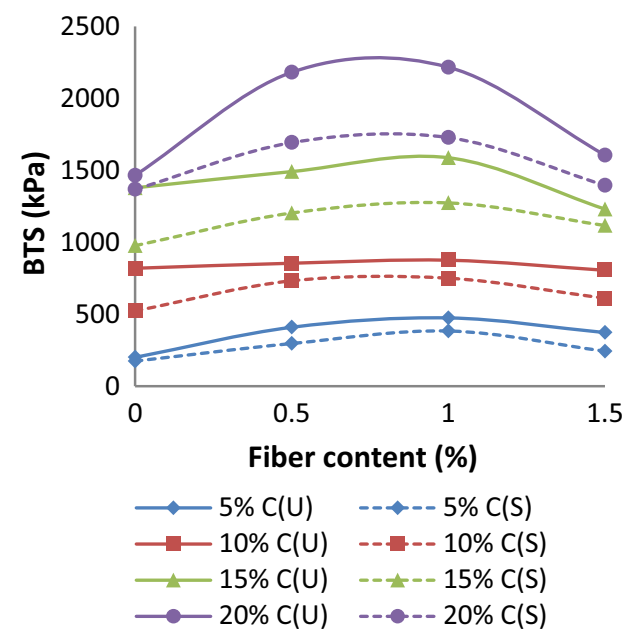

(c) 
during the first phase of curing and $20.4 \%$ during second phase of curing. For the mix having next higher cement contents $(10 \%)$, the average increase in corresponding phases are observed to be 29 and $32 \%$, i.e., almost same. However, in case of the mix having $15 \%$ cement content, the average increase is observed to be marginal (19\%) during the initial phase of curing whereas the same is found to be considerable (74\%). For the mix containing $20 \%$ cement contents, the average increase in the tensile strength during either phase of curing is observed to be almost same, i.e., 32.2 and $34.72 \%$ respectively.

It can be said that all the mixes having different cement contents and various curing period yields optimum performance with respect to the tensile strength at $1 \%$ fiber contents in almost all the cases, barring few exceptions. It is also seen that the strength is less in cases of the soaked samples. The study of the aspect of effect of curing period on mixes with different combinations of cement and fiber contents indicates that the strength of all mixes increases with increase in curing period. In the beginning, rapid gain in strength is observed. However, the rate of gain in strength decreases with further increase in curing period in most of the cases.

Bandopadhyay and Bhattacharjee [15] reported indirect tensile strength of cement stabilized fly ash mixes. The tensile strength of fly ash-cement mixes was evaluated and the cement contents were varied such as 4, 6, 8, 10, 12, 14 and $16 \%$. The samples were air cured for 28, 56 and 90 days. When the tensile strength of the mix with $6 \%$ cement obtained after 28 days curing is compared with that of the cement stabilized fly ash mix having $5 \%$ cement contents considered in the present investigation, it is observed that the strength obtained in the present investigation is $175 \mathrm{kPa}$ which is more than that reported in the literature $(134 \mathrm{kPa})$ [15]. There is fair agreement in the results although cement contents used in either study are slightly varying.

\section{Conclusions}

Some of the broad conclusions deduced from the present study are as follows:

1. The stabilization of the fly ash with cement alone or in conjunction with polypropylene fibers is effective in enhancing the UCS and BTS parameters. Slight addition of cement in fly ash enhances its performance and reinforcement with fiber further increases its strength.

2. The effect of cement and fiber contents along with the curing period and soaking condition is significant on the performance evaluation of cement stabilized and fiber reinforced fly ash mixes. The addition $1 \%$ fiber in the mix is found to yield optimum performance in case of either sample, i.e., un-soaked and soaked. Further, the use of $15 \%$ cement seems to be feasible. The use of cement beyond $20 \%$ shall although enhance the strength, will not be economically viable. The addition of little amount of cement to the fly ash increases the stiffness of the mixes.

3. An increase in curing period increases the strengths (UCS and BTS). This is attributed to the formation of pozzolanic reaction with the addition of cement. The gain in strength is rapid during the initial phase of curing. The strengths for the un-soaked samples are higher as compared to that for soaked samples.

4. The randomly distributed fibers limit the potential planes of weaknesses and also prevent the formation of cracks. The fiber reinforced specimens exhibited more ductile behavior.

5. Various studies have indicated that mixing of polypropylene fiber can increase the strength of soils to make them suitable for construction, especially, in the sub base. It is true for fly ash as well.

This investigation underscores the effective utilization of the industrial waste such as fly ash in conjunction with small amounts of cement and polypropylene fiber reinforcement as a sustainable civil engineering material.

\section{References}

1. Kaniraj SR, Havanagi VG (2001) Behavior of cement stabilized fiber reinforced fly ash soil mixtures. ASCE J Geotech Geoenviron Eng 127(7):574-584

2. Chauhan MS, Mittal S, Mohanty B (2008) Performance evaluation of silty sand subgrade reinforced with fly ash and fiber. Geotext Geomembr 26(5):429-435

3. Chore HS, Dhole SS, Abnave SB, Shinde SS, Kumthe AA, Kamerkar SG (2011) Performance evaluation of polypropylene fibers on sand-fly ash mixtures in highways. J Civ Eng (IEB) 39(1):91-102

4. Sadek S, Najjar SS, Freiha F (2010) Shear strength of fiber reinforced sand. ASCE J Geotech Geomech Eng 136(3):490-499

5. Kumar P, Mehndiratta HC, Chandranarayana Singh SP (2005) Effect of randomly distributed fibers on fly-ash embankment. J Inst Eng (India) 86(5):113-118

6. Tang C, Shi B, Gao W, Chen F, Cai Y (2007) Strength and mechanical behavior of short polypropylene fiber reinforced and cement stabilized clayey soil. Geotext Geomembr 25(3):194-202

7. Kalantari B, Prasad A, Haut Bujang BK (2012) Use of cement, polypropylene fibers and optimum moisture content values to strengthen peat. Int J Phys Sci 7(8):1276-1285

8. Kaniraj SR, Gayatri V (2003) Geotechnical behavior of fly ash mixed with randomly oriented fiber inclusions. Geotext Geomembr 21(3):123-149

9. Kumar P, Singh SP (2008) Fiber reinforced fly ash sub-bases in rural roads. ASCE J Transp Eng 134(4):171-180

10. Vaidya MK, Chore HS, Kousitha P, Ukarande SK (2013) Geotechnical characterization of cement-fly ash-fibers mix. IOSR J Mech Civ Eng 49(4):60-66 
11. IS: 4031 (First Revision) (1988) Methods of physical tests for hydraulic cement. Bureau of Indian Standards (BIS), New Delhi

12. IS: 2720 (Part VII) (1965) Determination of moisture content dry density relation using light compaction. Bureau of Indian Standards (BIS), New Delhi

13. Setty KRNS, Rao SVG (1987) Characteristics of fiber reinforced lateritic soils. In: Proceedings of the Indian Geotechnical Conference, vol 1, pp 329-333
14. IS: 2720 (Part X) (1973) Methods of test for soils: Determination of unconfined compression strength. Bureau of Indian Standards (BIS), New Delhi

15. Bandopadhayay K, Bhattacharjee S (2010) Indirect tensile strength test of stabilized fly ash. In: Proceedings of the Indian Geotechnical Conference, Mumbai, vol 1, pp 279-282 